\title{
The intrinsic strength of non-covalent interactions described by coupled cluster theory.
}

\author{
Vytor Oliveira $^{1 *}$, Elfi Kraka ${ }^{1}$ \\ ${ }^{1}$ Computational and Theoretical Chemistry Group (CATCO), Department of Chemistry, Southern \\ Methodist University, 3215 Daniel Ave, Dallas, Texas 75275-0314, USA.voliveira@smu.edu \\ Keywords: halogen bond, non-covalent, local modes.
}

\section{Introduction:}

Directional non-covalent interactions guide self-assembly of complex supramolecular structure, stabilize the tertiary structure of proteins and DNA/RNA, lead to drugreceptor recognition to name a few applications [1]. Recently, our group have systematically investigated more than 300 complexes formed by different kinds of noncovalent interactions [2-4]. We compare here the strength of some of these complexes including also tetrel bonded complexes not previously studied.

\section{Computational Methods:}

In the present study we combine vibrational spectroscopy with high accuracy $\operatorname{CCSD}(\mathrm{T})$ /aug-cc-pVTZ calculations to investigate the strength of 14 different complexes involving hydrogen $(\mathrm{HB})$, halogen $(\mathrm{XB})$, chalcogen $(\mathrm{ChB})$, pnicogen $(\mathrm{PnB})$ and tetrel bond $(\mathrm{TrB})$ (Figure 1). The parameter chosen for the quantitative evaluation of the strength of these interactions is the local stretching force constant $\left(\mathrm{k}^{\mathrm{a}}\right)$. The $\mathrm{k}^{\mathrm{a}}$ of a noncovalent interaction measures the rate of change in the energy for an infinitesimal change in the intermonomer separation, providing a way to probe the strength of a bond without having to break it.

\section{Results}

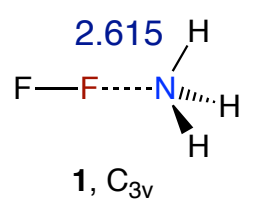<smiles>[3H]NC(=O)OC(C)(C)C</smiles>

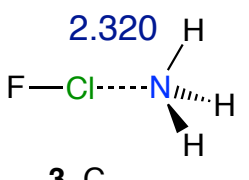

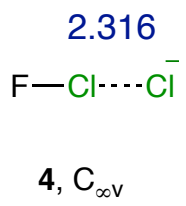

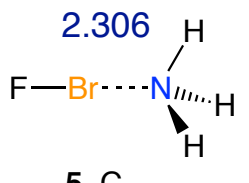<smiles>[1H][C@@H](F)S(C)(=O)=O</smiles>

6. $\mathrm{C}_{3 \mathrm{v}}$

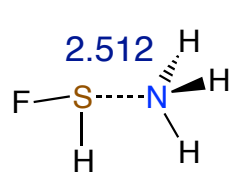

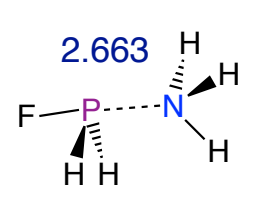

8, $C_{\text {s }}$

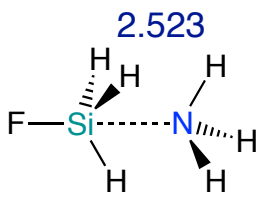

9, $\mathrm{C}_{3 \mathrm{v}}$
5, $\mathrm{C}_{3 \mathrm{v}}$<smiles>[1H][NH+](F)[Si]([2H])(F)F</smiles>

10, $C_{3 v}$

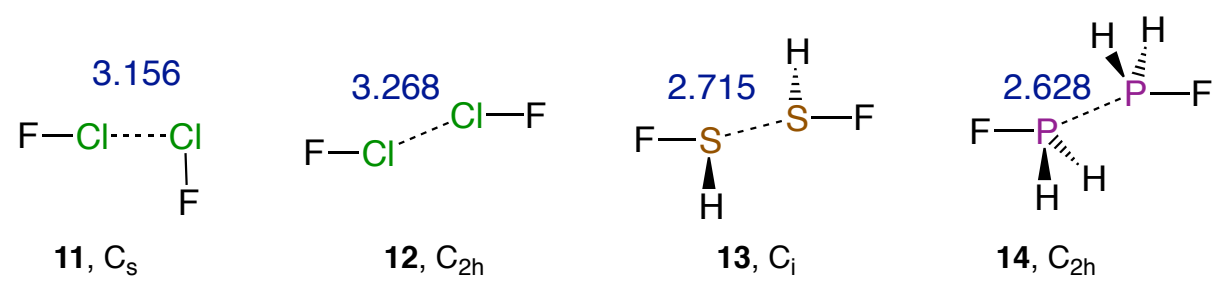

Figure 1. Representation of 14 non-covalently bonded complexes with intermolecular distances. 
Table 1. Binding energies $(\Delta E)$ in $\mathrm{kcal} / \mathrm{mol}$, local stretching forces constants $\left(\mathrm{k}^{\mathrm{a}}\right)$ in $\mathrm{mdyn} / \AA \mathrm{A}$ and type of non-covalent interaction for complexes 1-14.

\begin{tabular}{|c|c|c|c|c|}
\hline \# & Complex & $\Delta \mathrm{E}(\mathrm{kcal} / \mathrm{mol})$ & $k^{a}$ (mdyn/Å) & Type \\
\hline 1 & $\mathrm{~F}_{2} \cdots \mathrm{NH}_{3}$ & 1.7 & 0.062 & XB \\
\hline 2 & $\mathrm{Cl}_{2} \cdots \mathrm{NH}_{3}$ & 4.4 & 0.132 & XB \\
\hline 3 & $\mathrm{FCl} \cdots \mathrm{NH}_{3}$ & 9.4 & 0.311 & $\mathrm{XB}$ \\
\hline 4 & $\mathrm{FBr} \cdots \mathrm{NH}_{3}$ & 14.1 & 0.587 & XB \\
\hline 5 & $\mathrm{FCl} \cdots \mathrm{Cl}^{-}$ & 29.0 & 0.855 & $X B$ \\
\hline 6 & $\mathrm{FH} \cdots \mathrm{NH}_{3}$ & 12.1 & 0.353 & $\mathrm{HB}$ \\
\hline 7 & $\mathrm{FSH} \cdots \mathrm{NH}_{3}$ & 7.6 & 0.194 & ChB \\
\hline 8 & $\mathrm{FPH}_{2} \cdots \mathrm{NH}_{3}$ & 6.1 & 0.144 & $P n B$ \\
\hline 9 & $\mathrm{FSiH}_{3} \cdots \mathrm{NH}_{3}$ & 5.9 & 0.103 & $\operatorname{TrB}$ \\
\hline 10 & $\mathrm{SiF}_{4} \cdots \mathrm{NH}_{3}$ & 8.9 & 0.678 & $\operatorname{TrB}$ \\
\hline 11 & $(\mathrm{FCl})_{2}$ & 1.2 & 0.054 & XB \\
\hline 12 & $(\mathrm{FCl})_{2}$ & 0.7 & 0.027 & $X B$ \\
\hline 13 & $(\mathrm{FSH})_{2}$ & 3.6 & 0.097 & ChB \\
\hline 14 & $\left(\mathrm{FPH}_{2}\right)_{2}$ & 4.9 & 0.143 & $\mathrm{PnB}$ \\
\hline
\end{tabular}

\section{Discussion:}

The halogen bond strength depends on the polarizability of the halogen, the polarizing power of its substituent and the electron donor ability of the halogen-acceptor (complexes 1-5). By increasing the polarizability of the halogens (complexes $\mathbf{1}, \mathbf{3}$, and 4) a non-covalent interaction which is stronger than hydrogen bond (complexes 6) can be achieved. Halogen bond is stronger than the chalcogen, pnicogen or tetrel bonds formed by taking ammonia as a prototypical electron donor in monofluorinated compounds (complexes 3, 7, 8, 9). Complex 10 forms a stronger interaction than 3 (evidenced by a large $\mathrm{k}^{\mathrm{a}}$ ). However, its $\Delta \mathrm{E}$ is lower due to the energetic cost involved in the reorganization of the electronic structure upon complex dissociation, evidencing the limitations of $\Delta \mathrm{E}$ as an intrinsic strength descriptor. Halogen compounds form the weakest homodimers due to the poor electron donor ability of halogens (complexes 1114).

\section{Conclusions:}

The local stretching force constants provide a direct and reliable measure of the intrinsic strength of a noncovalent interaction. Halogen bond strength can be easily tuned, making it a versatile tool to be used in the development of new materials. Other types of non-covalent interactions involving main-group elements such as pnicogens and chalcogens are especially useful in systems where a single monomer acts as electrondonor and electron-acceptor as it was shown for the homodimers.

\section{References:}

1. Cavallo, P. G. et al, Chem. Rev., 2016, 116, 2478-2601.

2. Oliveira V., Kraka E., Cremer D.; Phys. Chem. Chem. Phys., 2016, 18:33031-33046.

3. Oliveira V., Kraka E., and Cremer D.; Inorg. Chem., 2017, 56(1):488-502.

4. Oliveira V., Cremer D., and Kraka E.; J. Phys. Chem. A, 2017,121(36):6845-6862.

5. Oliveira V. and Kraka E.; J. Phys. Chem. A, 2017, 121 (49), 9544-9556. 